\title{
Awareness of the phototoxic effects of sunlight among South African university students
}

\author{
†A Oduntan, $¥$ P Clarke-Farr, ${ }^{\S}$ R Hansraj and $\uparrow_{A}$ C Carlson
}

$\dagger$ § Discipline of Optometry, Faculty of Health Sciences, University of KwaZulu Natal, P Bag X54001, Durban, 4000 South Africa

$\$$ Department of Ophthalmic Sciences, Faculty of Health and Wellness Sciences, Cape Peninsula University of Technology, PO Box 652, Cape Town, 8000 South Africa

๑ Department of Optometry, University of Johannesburg, PO Box 524 Auckland Park, 2000 South Africa

$\uparrow<$ oduntanoa@ukzn.ac.za>

Received 18 May 2010; revised version accepted 30 September 2010

\begin{abstract}
Due to the depletion of the atmospheric ozone, there is currently a great concern for the phototoxic effects of sunlight on humans worldwide. The purpose of this study was to evaluate the awareness of the phototoxic effects of sunlight among a sample of South African university students. A questionnaire on awareness of the adverse effects of excessive exposure to sunlight was completed by the participants and findings were analyzed. Ages of the participants $(n=1832)$ ranged from 17 to 55 years (mean $=21.03 \pm 3.44)$ and there were $43.7 \%$ males and $56.3 \%$ females. Many, $(73.9 \%)$ agreed that excessive exposure to the sun is harmful to health, but only $56.9 \%$ could adequately explain how it is harmful to health. Many, $(68.2 \%)$ agreed that fair-skinned individuals are more likely to be affected by the sun than dark-skinned ones. Only
\end{abstract}

\section{Introduction}

Radiation from sunlight has some form of biological effects on humans, some of which can be very dangerous to health. Exposure to UV radiation
$52 \%$ reported that childhood exposure to sunlight is more dangerous than adulthood exposure. A few $(32.9 \%)$ agreed that short term intensive exposure was more dangerous than chronic regular moderate exposures. Although $72.3 \%$ had heard about ultraviolet (UV) radiation, only $47.1 \%$ had heard of cataracts and fewer $(25.7 \%)$ agreed that cataracts can be caused by UVR exposure. A few (28.7\%) had heard of macular degeneration, but only $17.6 \%$ agreed that it can be caused by UVR. Although awareness was good in certain aspects, it was poor in others; suggesting the need for an awareness campaign among South Africans. It is recommended that the awareness campaign should include avoidance of excessive exposure and the use of appropriate protective devices. ( $S$ Afr Optom 2010 69(3) 146-151)

Key words: Survey of phototoxicity, ultraviolet radiation, cataract, macular degeneration.
(UVR) is generally considered to be detrimental to human health and the major natural source of UVR is sunlight, although exposure to artificial sources in the workplace can also emit UVR ${ }^{1,2}$. There is a general agreement from epidemiological studies that expo- 
sure to UVR is a major cause of each of the common types of skin cancer such as basal cell carcinoma, squamous cell carcinoma and melanoma ${ }^{3,4}$. The skin of the eyelids may be affected by each of these carcinomas as well as melanoma. Age and latitude-related factors have been found to influence melanoma rates 5 and exposure at a young age has been reported to be more detrimental than adulthood exposure ${ }^{3}$.

Excessive exposure to solar UV and infra-red (IR) radiations can damage various ocular tissues ${ }^{6-8}$. Ultraviolet radiation exposure can result in eye diseases such as cataract ${ }^{9}$, age-related macular degeneration ${ }^{10,11}$ and neoplasms ${ }^{12,13}$. Epidemiological and experimental reports agree on the association of sunlight with the formation of cortical and posterior subcapsular cataracts $^{9}, 14,15,16$. Age related macular degeneration is a major cause of visual impairment among the elderly, especially Caucasians and those with light irides ${ }^{10}$ and there are many recent reports in support of the association between sunlight and the condition ${ }^{11,17-19}$. Ocular surface squamous neoplasia (OSSN) involving the conjunctiva and cornea commonly occur among those who live in geographic areas exposed to high levels of UVB ${ }^{12}$. Basal cell carcinoma in the eye has also been considered to be due to $\mathrm{UVR}^{20}$. Pterygium occurs most commonly in very sunny climates and there is evidence that it is also related to solar UVR exposure ${ }^{21-23}$. Population studies have supported the views that absorption of UVR plays a role in the development of a pterygium ${ }^{24-26}$.

South Africa has extensive coastal areas and many teenagers and adults spend a significant amount of time at the beaches. Also, many people spend a large amount of time outdoors for vocational or social reasons. No records of any previous studies on the adverse effects of sunlight and prevention practices in South Africa could be found. Also, there is no existing information on UV related systemic and eye diseases in the country. Therefore, it was of interest to the researchers to assess the awareness of a sample of the population on the adverse effects of exposure to solar radiations. Findings of this study may dictate the need for awareness campaigns and behaviour modification towards sunlight. These would help to prevent diseases which might be related to solar-radiation.

\section{Methods}

Approvals to conduct this study were obtained from the Research and Ethics Committees of the University of Limpopo, South Africa, where the first author was formally located. A questionnaire was used as the instrument for data collection. Copies were distributed to the students at the University of Limpopo, University of Johannesburg, University of KwaZulu Natal and the Cape Peninsula University of Technology. These universities were chosen because the authors were staff members of the universities. Class lists of randomly selected departments were obtained with the permission of the Deans of Faculties and Directors of Schools. Systematic sampling was used to select the participants. Participants were informed of the purpose and procedure involved in the study and those who agreed to partake in the study signed the consent forms. They were assured of the confidentiality of information provided. Copies of the questionnaire were distributed to the participants by the researchers and trained assistants. Participants were required to respond 'yes', 'no', 'no idea' or provide answers to given questions. The response rate was $87 \%$. Data from the questionnaire were analysed with the descriptive and Pearson's chi squared statistics of the Statistical Package for Social Sciences (SPSS) computer programme.

\section{Results}

A total of 1855 questionnaires were received from the participants, but $1.24 \%$ questionnaires were rejected due to grossly incomplete data. The ages of the 1832 respondents included in the analysis ranged from 17 to 55 years $($ mean $=21.03 \pm 3.4)$. They included $43.7 \%$ males and $56.3 \%$ females. Many, $(68.3 \%)$ were blacks, $20 \%$ were whites, $3.4 \%$ were Indians and $7.4 \%$ were coloureds. Others, (0.9\%) did not indicate their races. Percentage responses to questions on sunlight exposure (Questions 1-6) and sunlight in relation to cataract and macular degeneration (Questions 7-11) are illustrated in Figures 1 to 6. Responses were good on the knowledge of sunlight exposure (Figure 1) and race had a consistently significant influence on the responses ( $p<0.05$, Figure 2$)$. Females appeared to have greater awareness as they had statistically significant greater correct responses than males in most of the questions 7-9 (Figure 3). For questions on sunlight in relations to cataract and macular degeneration, responses were generally poor 
(Figure 4) as correct responses were less than 50\% in four out of the five questions. Although Indians and whites appeared to have greater awareness, race factor was significant only, in questions 7,8 and 10 (Figure 5). Although, in general, females appeared to have greater awareness than males, the difference was only significant in question 8 (see Figure 6).

Although $73.9 \%$ of the respondents agreed that excessive exposure to sunlight could be harmful to health, only $56.9 \%$ were correct in their explanation of how it could be harmful. The responses on UVR, cataract and macular degenerations in relation to race are shown in Tables 3 and 4, and in relation to gender are shown in Tables 5 and 6 . Gender was not a significant factor in all the responses $(p>0.05)$, except hearing about cataract. Among those who had heard of UVR, $50.3 \%$ heard about it from a teacher/lecturer, $25.9 \%$ from books/ magazines, $(18.7 \%)$ from radio/ television and others $(5 \%)$ from other sources. The highest proportion of those who had heard it from books $(64.2 \%)$ were Blacks and the highest proportions of those who heard it from books/magazines $(78 \%)$ or radio/ television (64\%) were Whites. More females, $(29.1 \%)$ than males $(21.7 \%)$ had heard of it from books or magazines. There was no significant racial or gender factor on the various sources of awareness about the UVR $(p>0.05)$. The responses to the following questions are illustrated in Figures 1 -6 :

1. Is excessive exposure to the sun harmful to your health?

2 Can exposure to sunlight result in skin cancer?

3. Are fair skinned persons more likely to be affected by the sun than dark skinned?

4. Does greater exposure to the sun result in greater risk of cancer?

5. Is excessive childhood exposure to UV more dangerous than adulthood exposure?

6. Does term intensive exposure to the sun more dangerous than chronic moderate exposure?

7. Have you heard of ultraviolet radiation?

8. Have you heard of a cataract?

9. Can UVR from the sun cause cataract?

10. Have you heard of macular degeneration?

11. Can UVR from the sun cause macular degeneration?

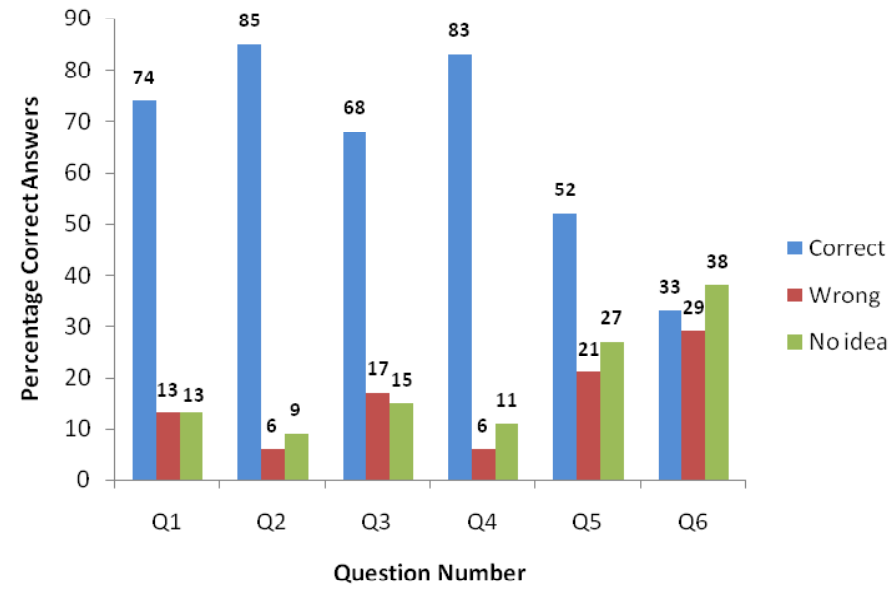

Figure 1: Showing the percentages of the correct, wrong and 'no idea' responses to questions 1-6. Those who did not provide answers were considered as having no idea. For most of questions, correct answers were more frequent than incorrect or 'no idea' responses.

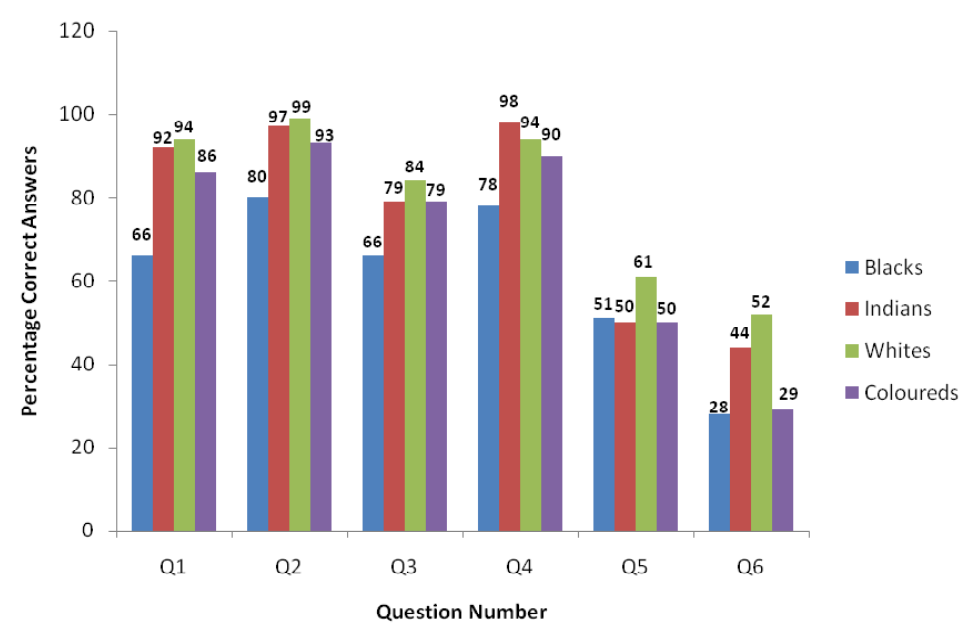

Figure 2: Showing the percentages of respondents within each race who gave the correct answers to questions 1-6. Indian and White respondents consistently appeared to have greater awareness on sunlight exposure.

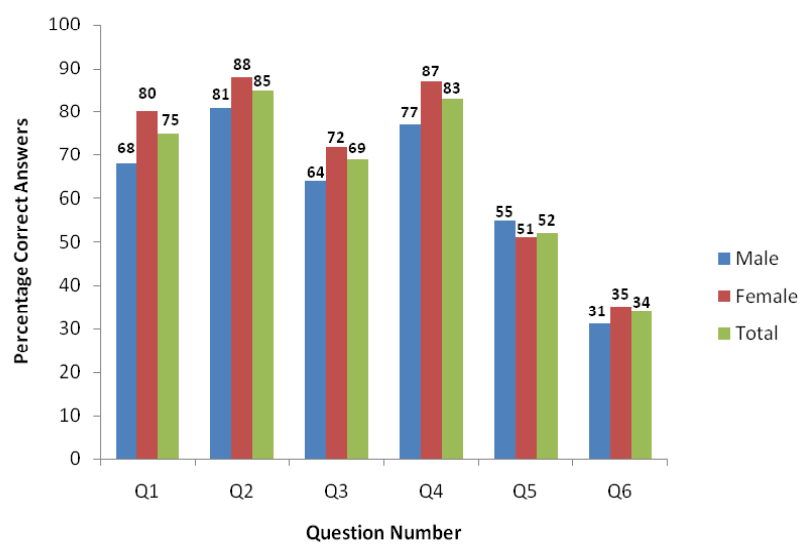

Figure 3: Showing the percentages of respondents within each gender who gave the correct answers. The percentages of the respondents who provided the correct answers among those who responded to each question are shown as total. Females appeared 
to have greater awareness than males.

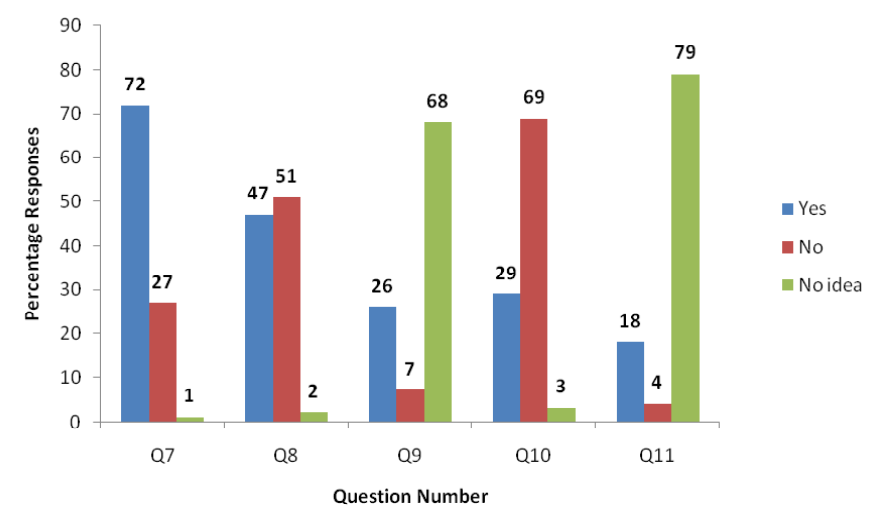

Figure 4: Showing the percentages of respondents who reported 'Yes', 'No' and 'no idea' to questions 7-11. Generally, correct responses were low, being less than $50 \%$ in most of the questions.

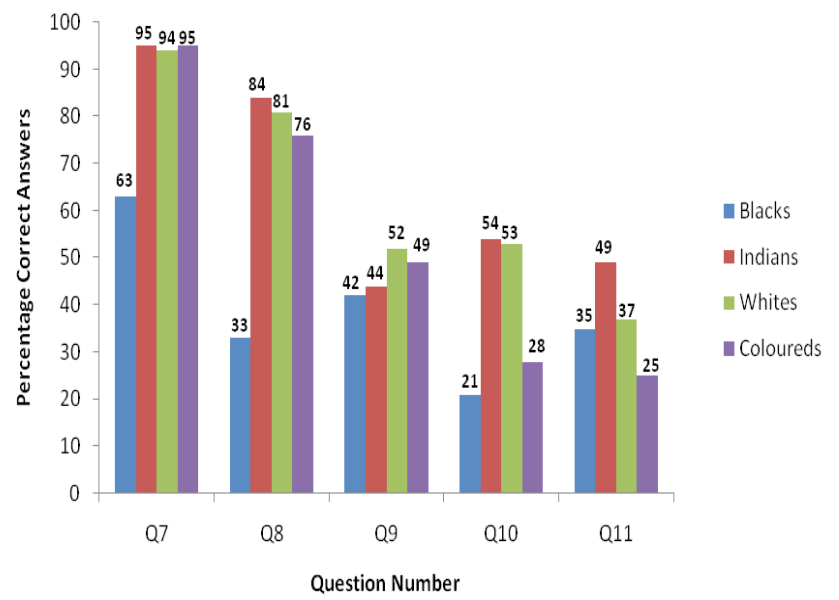

Figure 5. Showing the percentages of correct responses within each race for questions 7-11. The Indians and Whites appeared to have greater knowledge on these aspects. Correct responses were higher for having heard of UV and cataract (questions 7 and 8)

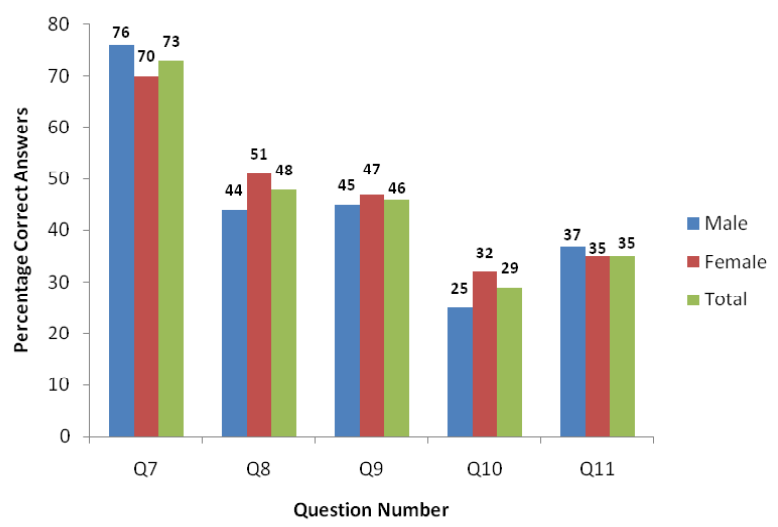

Figure 6. The percentages of respondents within each gender who gave correct answers to questions 7-11. The percentages of the respondents who provided the correct answers among those who responded to each question are shown as total.

\section{Discussion}

With the current epidemic of HIV/AIDS, tuberculosis and malaria in many parts of Africa, the focus of many governments and non-governmental organizations (NGOs) on the continent is on these areas. Blindness and other health issues are receiving less attention. As excessive exposure of the eyes to sunlight has serious eye health implications, this article is aimed at providing information on the awareness of health risks on exposure to sunlight among South African university students. Findings will therefore, dictate the need for awareness campaigns against unnecessary exposure in order to reduce phototoxic effects of sunlight among South Africans. The majority of the subjects in this study were in their twenties and those in this age group are more likely to spend a long time in the sun for leisure purposes. Also, they are the age groups who are child bearing or likely to start having children soon, so it is important to know that they are aware of the adverse effects of solar radiation, so that they could educate and protect their children against the adverse effects as well.

Although $74 \%$ of the respondents in this study reported 'yes' to the question that excessive exposure to the sun is harmful to health (Figure 1); only $56.9 \%$ gave the correct explanation for how it could be harmful to health. These findings are a significant cause for concern, particularly considering that the sample were university students who were considered to be more aware of this aspect than the general population. Also, the $31.8 \%$ of the respondents who either responded 'no' or did not respond to the question that fair-skinned individuals are more likely to be affected by the sun than dark-skinned ones (Figure 1) is of concern because it has been well reported that those with fair skin are at greater risk for eye problems ${ }^{10}$.

Although a large proportion $(82.8 \%)$ responded 'yes' to the statement that greater exposure to sunlight can result in a greater risk of cancer; a higher percentage is desirable. Only $52 \%$ responded 'yes' to the question: Is excessive childhood exposure to sunlight more dangerous than adulthood exposure? Also, only $32.9 \%$ reported 'yes' to the question: Is short term intensive exposure more dangerous than chronic regular moderate exposure (Figure 1)? These are considered poor and reflect the need for educational campaigns 
on the adverse consequences of sunlight exposure, especially with regard to childhood exposure.

The White respondents in this study were more aware of the adverse effects of the sun than other races (Figure 2). This is good because it has been reported that those with light skin are more prone to skin cancer and other adverse effects of the sun than the dark-skinned ones. However, it has been reported that, although skin cancer is less common in persons with darker skin colour than in the light skinned Caucasians, it is often associated with greater morbidity and mortality in the darker skinned individuals ${ }^{28}$. Therefore, protection against the adverse effects of sunlight should be taken seriously by all persons, irrespective of skin colour.

The current study found that females appeared to have greater awareness of the risks of exposure to sunlight than the males in many of the responses (Figure 3); which is in agreement with previous studies ${ }^{29,} 30$. A possible explanation for this trend could be the exposure to knowledge based on reading material. Anecdotal evidence suggests that females are more likely to read these magazines than males and thus become more aware of the effects of UVR. It was also found that more females $(29.1 \%)$ than males $(21.7 \%)$ heard about UVR from books or magazines. Distinct gender differences were also observed in a study by Jansson $e t a l^{31}$ on the evaluation of a health education intervention regarding skin cancer prevention among students in a preschool vocational programme wherein females reported a significantly greater interest in protecting children than their male counterparts. Branstorm et al 32 also found that women used protective measures more often than men when in the sun, which supports the greater awareness among females in the present study.

Knowledge of cataract and macular degeneration and the role of UV in their aetiology was poor among all races and genders (Figure 4-6). Less than half $(47.1 \%)$ of the respondents reported to have heard of a cataract and only $25.7 \%$ were aware that it can be caused by UVR from the sun (Figure 4). These findings are of concern since according to the World Health Organisation (WHO) ${ }^{27}$, cataracts remain the leading cause of blindness globally, especially in the developing countries. Although several studies ${ }^{11,17-19}$ have associated macular degeneration to UV exposure, only $28.7 \%$ of the respondents reported to having heard of macular degeneration and only $17.6 \%$ agreed that UV radiation from the sun could cause it. Therefore, an awareness campaign among the general population around the risks of UV exposure and its prevention could help reduce the risk of developing these conditions in the country.

\section{Conclusion}

While the responses showed that the respondents were informed in certain areas, they had poor awareness in others. In view of these findings, there is a need for an awareness campaign about excessive solar radiation exposure in South Africa. Such campaigns should include avoidance and protective strategies against excessive exposure to solar radiation. These would include the use of appropriate sunshades, wide brim hats, appropriate protective clothing and umbrellas and the use of appropriate eye protection devices to protect against solar radiations as suggested by previous authors ${ }^{33}, 34$.

\section{Acknowledgement}

The authors acknowledge the assistance of Mrs Fikile Nkwanyana in the data analysis. We are grateful to all the participants in this study and the South African universities that provided the materials used

\section{References}

1. Thieden E, Philipsen PA, Heydenreich J and Wulf, HC. Ultraviolet radiation exposure related to age, sex, occupation, and sun behaviour based on time-stamped personal dosimetry readings. Arch Dermatol 2004140 197-203.

2. Shah CP, Weis E, Lajous M, Shields JA and Shields CL. Intermittent and chronic ultraviolet light exposure and uveal melanoma: a meta-analysis. Ophthalmol 20051121599 1607.

3. de Gruijl FR, Longstreth J, Norval M, Cullen AP, Slaper H, Kripke M L, Takizawa Y and van der Leun JC. Health effects from stratospheric ozone depletion and interactions with climate change. Photochem Photobiol Sci 20032 1628.

4. MacKie RM. Long time health risk to the skin of ultraviolet radiation. Progr Biophys Mol Biol 200692 92-96.

5. Bulliard J-L, Hugh A. Site-specific risk of cutaneous malignant melanoma and pattern of Sun exposure in New Zealand. Intern J Cancer 200085 627-632.

6. Johnson GJ. The environment and the eye. Eye 200418 1235-1250. 
7. Gallagher RP, Lee TK. Adverse effects of ultraviolet radiations: A brief review. Progr Biophys Mol Biol 200692 119131.

8. Zuclich JA, Lund DJ, Stuck BE. Wavelength dependence of ocular damage thresholds in the near-IR to far-IR transition region: proposed revisions to maximum permissible exposures. Health Phys 200792 15-23.

9. Mafia K, Gupta R, Kirk M, Wilson L, Srivatava, OP, Barnes $\mathrm{S}$. UV-A induced structural and functional changes in human lens deamindated by B-crystallin. Mol Vision 2008 14 234-248.

10. Wang JJ, Jakobsen K, Smith W, Mitchell P. Five-year incidence of age-related maculopathy in relation to iris, skin or hair colour and skin sun sensitivity: the Blue Mountain Eye Study. Ophthalmol 200331 317-321.

11. Tomany SC, Cruickshanks KJ, Klein R. Sunlight and the 10 year incidence of age- related maculopathy: the Beaver Dam Eye Study. Arch Ophthalmol 2004122 750-757.

12. Lee GA, Hirst LW. Ocular surface squamous neoplasia. Surv Ophthalmol 199539 429-450.

13. Basti S, Macsai MS. Ocular surface squamous neoplasia: A review. Cornea 200322 687-704.

14. Zigman S. The role of sunlight in human cataract formation. Surv Ophthalmol 198327 317-325.

15. Truscotta JW. Age related nuclear cataract-oxidation is the key. Exp Eye Res 200580 709-725.

16. Varma SD, Hedge KR, Kovtun S. UV-B induced damage to the lens in vitro: prevention by caffeine. J Ocul Pharmacol Therap 200824 439-444.

17. Delcourt C, Carriere I, Ponton-Sanchez A, Fourrey S. Light exposure and the risk of age-related macular degeneration. Arch of Ophthalmol 2001119 1463-1468.

18. Beatty S, Koh H, Henson D, Boulton M. The role of oxidative stress in the pathogenesis of age-related macular degeneration. Surv Ophthalmol 200045 115-134.

19. Ambati J, Ambati B, Yoo SH, Lanchuley S, Adamis AP. Age-related macular degeneration: Etiology, pathogenesis and therapeutic strategies. Surv Ophthalmol 200348257 293.

20. Birt B, Cowling I, Coyne S, Michael G. The effect of eye's surface topography on the total irradiance of ultraviolet radiation on the inner canthus. J Photochm Photobiol B: Biology 200787 27-36.

21. Hirst LW, Axelson RA Schwab I. Pterygium and associated ocular surface squamous neoplasm. Arch Ophthalmol 2009 127 31-32.

22. Threlfall TJ, English DR. Sun exposure and pterygium of the eye: A dose-response curve. Am J Ophthalmol 1999128 280-287.

23. Di Girolamo N, Chui J, Coroneo MT. Pathogenesis of pterygia: role of cytokines, growth factors and matrix metalloproteinases. Progr Ret Eye Res 200523 195-228.

24. Wong TY, Foster PJ, Johnson GJ, Seah SK, Tan DT. The prevalence and risk factors for pterygium in an adult Chinese population in Singapore: The Tanjong Pagar Survey. Am J Ophthalmol 2001131 176-183.
25. Shiroma H, Higa A, Sawaguchi S, Iwase A, Tomidokoro A, Amano S, Araie M. Prevalence and risk factors of pterygium in a Southwestern Island of Japan: The Kumejima Study. Am J Ophthalmol 200948 766-771.

26. Nemesure B, Wu S-Y, Hennis A, Leske M.C. Barbados Eye studies group. Nine years incidence and risk factors for pterygium in the Barbados Eye Studies. Ophthalmol 2008115 2153-2158.

27. World Health Organization. Visual impairment and blindness. Fact Sheet No 282, 2009

28. Gloster HM, Neal K. Skin cancer in skin of colour. $J$ Am Acad Dermatol 200655 761-763.

29. Kristjansson S, Ullen H, Helgason AR. The importance of assessing the readiness to change sun-protection behaviour: A population-based study. Eur J Cancer 2004402773 2780.

30. Cinar ND, Cinar S, Karakoc A, Ucar F. Knowledge, attitudes and behaviors concerning sun protection/skin cancer among adults in Turkey. Pak J Med Sci 200925 108-112.

31. Jansson B, Boldeman C, Dal H, Ullen H. Skin cancer prevention in early childhood: An evaluation of a health education intervention among students in a preschool vocational programme. Health Edu J 200362 198-209.

32. Branstorm R, Ullen H, Brandberg Y. Attitude, subjective norms and perception of behavioural control as predictors of sun-related behavior in Swedish adults. Prev Med 2004 39 992-999.

33. Moore LA. Ocular protection from solar ultraviolet radiation (UVR) in sports: factors to consider when prescribing. S Afr Optom 200462 72-79.

34. Sheedy JE, Eldlich RF. Ultraviolet eye radiation: The problems and solutions. J Long Term Effects Med Implants 200414 67-71. 